\title{
Optimal growth with adaptation to climate change
}

\author{
Patrice Dumas* $\quad$ Minh Ha-Duong $^{\dagger}$
}

September 17, 2012

\begin{abstract}
We find that approximately a quarter of the world's productive capital could be sensitive to climate; therefore, this capital faces the risk of accelerated obsolescence in a world warming by an average of $0.2^{\circ} \mathrm{C}$ per decade. We examine the question of optimal adaptation to climate change in a vintage capital growth model without uncertainty. Along the optimal pathway, adaptation is proactive with an anticipation period of approximately twenty years. While there is additional investment in this scenario compared with a no-climate-change baseline, the overall cost to adapt is low relative to the potential losses from maladaptation. Over-investment in protection capital allows the economy to be consistently well-adapted to climate; thus, such a policy prevents transient maladaptation costs. Sensitivity analysis with an integrated assessment model suggests that costs could be ten times larger if adaptation only begins after vulnerable sectors are impacted.
\end{abstract}

Keywords: Climate change, adaptation, optimal growth, integrated assessment model.

\section{Introduction}

IPCC (2007) wrote that warming of the climate system is unequivocal. Continued greenhouse gas emissions at or above current rates would cause further warming and induce many changes in the global climate system during the 21 st century. These changes would probably be larger than those observed during the 20th century. Because many decision-makers already account for climate change in their investment choices, a certain amount of planned adaptation of human activities is occurring now; however, more extensive adaptation is required to reduce vulnerability to climate change.

\footnotetext{
*dumas@centre-cired.fr. Laboratoire de Météorologie Dynamique, Ecole Normale Supérieure, 24 Rue Lhomond, Paris, France. Centre de coopération internationale en recherche agronomique pour le développement We acknowledge financial support from the Ile de France region under the R2DS research programme and from the ANR research project AMTools. We would like to thank S. Hallegatte, C. Böhringer, EAERE participants and two anonymous reviewers for their useful comments.

†Patrice Dumas, Minh Ha-Duong. Centre International de Recherche sur l'Environnement et le Développement, Campus du Jardin Tropical, 45 bis, avenue de la Belle Gabrielle, 94736 Nogent-sur-Marne Cedex, France
} 
Adaptation can be defined as initiatives and measures to reduce the vulnerability of natural and human systems against actual or expected climate change effects. Various classes of adaptation exist: for example, anticipatory versus reactive, private versus public, and autonomous versus planned. Two specific examples are building up river or coastal dikes and the planting of more temperature shock-resistant crops in place of sensitive crops. This paper focuses on anticipatory adaptation to expected climate change in one of the most important of all human systems: the economy.

In a changing climate, two sources of impacts on the socio-economic system can be distinguished: an absolute component, associated with a hypothetically stable but warmer climate, and a transient component associated with a changing climate. There is a larger literature on the absolute component (Nordhaus and Boyer, 2000; Stern, 2006) than on the transient component (Kelly et al., 2005; Hallegatte, 2005). The absolute component of adaptation is explicitly studied in de Bruin et al. (2009) where adaptation to the absolute level of climate change damages is separated from the absolute damages. In this context, the trade-off between mitigation and adaptation is studied. In our view, the existence of adaptation implies that the transient component, associated with transitional adaptation costs, should receive more attention.

Reilly and Schimmelpfennig (2000) argued that a better understanding of adaptation is critical for assessing the long-term impacts of climate change and choosing the policy response. While several studies show that anticipatory adaptation is already occurring, others are less optimistic. Uncertainty may be part of the explanation, as the range of possible climate change outcomes is very wide, especially at the local level (Kopf et al., 2008; Hallegatte, 2009). Another part of the explanation is that perfect foresight is an ideal rarely found in reality, even when scientific knowledge indicates that society should reasonably expect an increasing pace of climate change in the near future.

In a world where rational investors should anticipate a $0.2^{\circ} \mathrm{Cglobal}$ warming per decade, two extreme and opposing views are commonly found in the existing literature on climate impacts: no adaptation, and total adaptation.

- The former assumption, also called "dumb farmer" or "no response", amounts to assuming that climate change is sufficiently sudden that societies are too inert and shortsighted to adapt effectively. This assumption allows the analyst to assess potential vulnerability, which may overestimate the true expected impacts.

- The total adaptation assumption amounts to assuming that economic agents perfectly anticipate future climatic conditions; in this scenario, adaptation is rapid and costless. This assumption allows the analyst to assess the potential for adaptation but may lead to an underestimate of the true expected impacts.

The literature on adaptation recognizes that there is a dynamic tradeoff to be made between the productivity loss caused by the changing climate and the resources allocated to adaptation. Kelly et al. (2005) argued that agents are hampered in their ability to instantly adapt to the changing climate for two reasons: input (e.g., capital) fixity and incomplete information regarding of climate change.

In this study, we explore the issue of capital fixity in contrast to the previous literature that focused on adaptation, uncertainty and learning (Schneider et al., 2000; 
O'Neill et al., 2006; Smit et al., 2000). For example, Kelly et al. examined the problem of adaptation to a small change amid large natural background variability. These researchers found that for agriculture in the Midwestern US, the costs of being not perfectly adapted are less than expected gains from climate change. In the case of coastal flooding, West et al. (2001) found that the costs of not adapting to the risk are small.

This paper is organized as follows. Section 2 demonstrates the importance of the problem at hand. Specifically, we empirically estimate how much of the world's current capital stock is somehow adapted to the climate and is therefore exposed to climate change. We disaggregated the global economy into 26 sectors and estimated each sector's vulnerability to climate change. Using data from the Global Trade Analysis Project (GTAP), we find that a significant share (approximately 25\%) of the world's capital stock appears to be sensitive to the climate.

Section 3 provides an analytical outline of the main features of the optimal investment plan. We assume perfect anticipation and look at optimal policies for addressing the accelerated obsolescence of capital caused by climate change.

Section 4 presents a more complex integrated assessment model of optimal growth and adaptation. The effects of climate change are represented as losses in economic efficiency incurred when the productive system is not in line with the current climate. The model does not include uncertainty, climate change mitigation, or any permanent damages (or benefits) linked with the absolute level of climate change.

Section 5 presents the main results. First, adaptation is proactive: along the optimal investment path, the protection capital installed is not perfectly adapted to the present climate but anticipates the future warmer conditions. Second, adaptation is almost complete: additional investment allows society to remain consistently well-adapted to climate along the optimal path. Third, costs are low: while climate change requires additional investments for adaptation, the overall cost to adapt is relatively low compared with the potential losses from maladaptation, and the overall utility loss is small in the end. Section 6 provides discussion and conclusions regarding these findings.

\section{Capital and adaptation to climate}

Our study takes a macroeconomic approach to the problem of adaptation. In certain sectors, the efficiency of capital may be negatively impacted by climate, but the impact can be offset by allocating specific resources to adaptation. This section aims to define our terminology and empirically assess two figures. One figure is the share of the world's capital stock that is exposed to present and future climate risks. The other figure is the share of the world's capital stock that is devoted to climate-proofing the previous lot. We use a weighted multi-criteria approach, adding up the different sectors of the world economy without making geographical refinements.

We build upon the conceptual distinction of productive, exposed and protection capital previously made by World Bank (2006, Annex K). We assume that a constant fraction $v$ of the economically productive capital is potentially impacted by climate risks. It will be called exposed capital. The accumulation of economic resources allocated to adaptation will be called protection capital. This covers measures that are long-lived, not directly productive, and specific to a given climate range. A canonical 


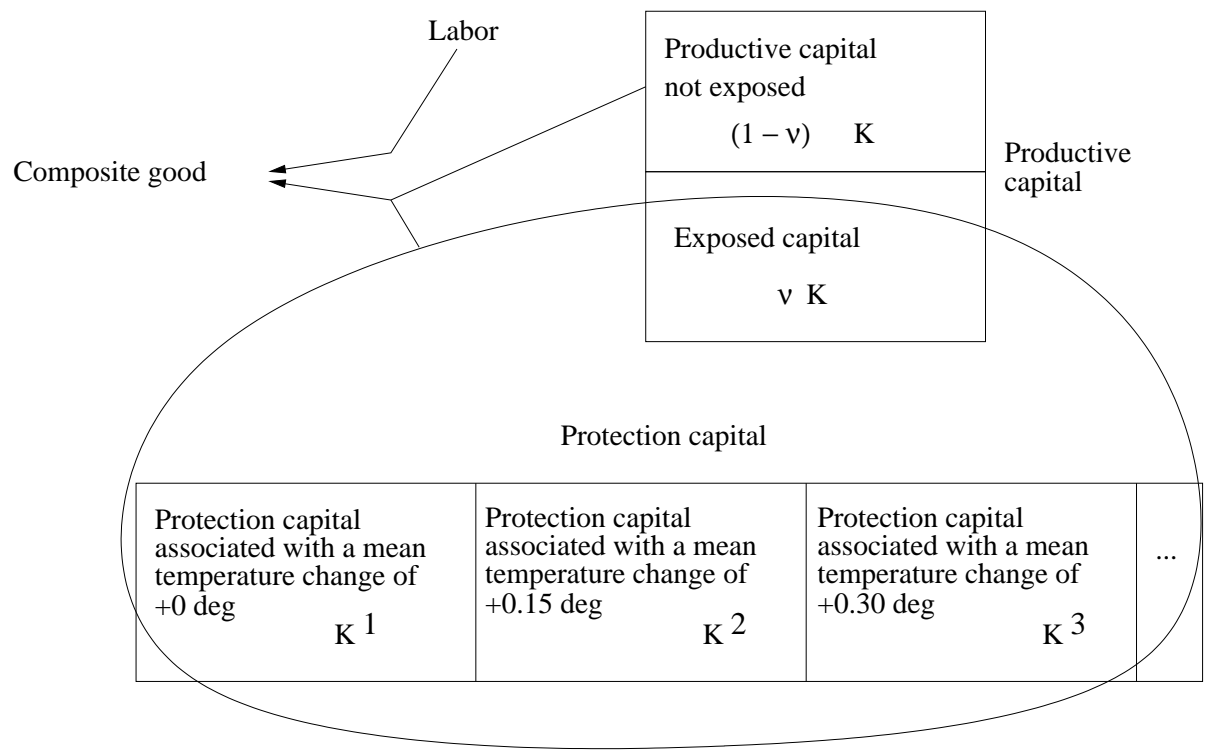

Figure 1: Three kinds of capital stock involved in adaptation to climate change. Exposed capital is the fraction of economically productive capital that is potentially impacted by climate change. Protection capital is specific, long-lived, non-productive ressources allocated to adaptation.

example of protection capital is hail guard nets. The combination of exposed capital and protection capital, as shown with a bubble figure 1, is called sensitive capital. This combination's productivity depends on the climate.

For example, water production and transport facilities have to be modified when precipitation and temperature regimes change: in certain places, the available water is no longer sufficient, while in other places, water may be more abundant than before. The bulk of the water system does not necessarily need to be changed. Only the parts that must be adjusted correspond to the concept of protection capital. Institutions and habits may also be considered to be akin to protection capital, although they are not present in national economic accounts. The health care system must be adapted to the climate; the relative resources demanded across seasons may change depending on the climate. Such a shift was demonstrated during the heat wave in Europe in 2003 (Salagnac, 2007).

Figure 1 illustrates how we combine these three kinds of capital in a production function. The originality of our model is that we assume that protection capital comes in various kinds, with each being adapted to a specific climate. In this conceptual framework, protective measures that improve the situation in all climates, such as building insulation, are considered to be part of productive capital. These measures include so-called "robust adaptation measures"; that is, measures taken in anticipation of climate change that remain efficient independent of the magnitude of the change. With 
this assumption, there is no possibility of having more robust adaptation measures in the future. We assume that the protection capital in place today is adapted to the past climate; that is, there is no possibility of foresight for climate change adaptation up to now. This assumption is justified because climate change adaptation only recently became a significant political goal. This assumption does not necessarily mean that we consider adaptation to past climates to be perfect, but rather that the current level of adaptation to today's climate is the reference level that may be attained in the future.

We now turn to the question of evaluating the share of economic activity that is vulnerable to climate and the amount of protection capital required to preserve this share. Empirically, this question can only be answered approximately.

We used a coarse disaggregation of the global economy and a qualitative multicriteria characterization of the sectors mapped into a quantitative scale. The GTAP (1997) database was used as a basis for an aggregation of the global economy in 26 sectors. Each sector was scored using a qualitative scale $(-,+$ and ++$)$ for three criteria:

1. Climate specificity: Is the organization of the sector identical across different climates or not? For example the water sector is specific because water supply and demand depends on the regional patterns of precipitation and evaporation.

2. Importance of outdoor activity in the sector.

3. Vulnerability to climatic extreme events.

Those criteria are considered to be linked with exposure and vulnerability to climate change. The scores are given in table 1. Criteria were linearly weighted to translate the qualitative scores into two quantitative indices, namely, a sensitivity index and a defensivity index.

The sensitivity index is used to determine the fraction of total capital considered sensitive. For each criterion, a + translates to a vulnerability of $20 \%$, and a ++ translates to vulnerability of $33 \%$. For example, for the transport sector, there is no specificity for climate; therefore, the associated vulnerability is $0 \%$. Transport is mildly vulnerable because it is an outdoor activity; it is assigned a + , which amounts to a vulnerability of $20 \%$. Finally, the transport sector is sensitive to extreme events that render transport infrastructure unavailable; therefore, the sector is assigned a ++ , which translates to vulnerability of $33 \%$ associated with extreme events. The resulting sensitivity index for the Transport sector is $0+20+33=53 \%$.

The defensivity index is used to determine the ratio of protection capital to sensitive capital. We assumed that climate specificity does not imply any need for protective measures, while sensitivity to extreme events implies a greater need for protective measures than does outdoor activity. Thus, the defensivity weights are $0,15 \%$ and $35 \%$ for specificity, outdoor activity, and sensitivity to extreme events, respectively. For example, this weighting scheme leads to $0 \cdot 0+0.2 \cdot 15+0.33 \cdot 35=15 \%$ for the transportation sector, as the third line of table 1 indicates.

Sectors were weighted according to their share of total capital revenues and their share in total value added to obtain a global, economy-wide figure. These weights, 
according to the GTAP database, are shown in the last columns of table 1 for each of the vulnerable sectors. The result is a global sensitivity index of $24-25 \%$, depending on the weighting used, and a defensivity index of $10 \%$. The exact shares of the sectors are affected by the weighting procedure, but the figures are not qualitatively different. These numbers will be used to calibrate the model in the following sections.

Our empirical results can be compared to the existing literature in three ways. First, this section's results indicate only the orders of magnitude. The procedure used in this section is heuristic, and a sensitivity analysis of these parameters is conducted later in the analysis. A degree of imprecision is to be expected for the question at hand, given that assessing absolute and relative stocks of capital can only be performed imprecisely; in addition systems of national accounts are not currently designed to measure climate change adaptation expenditures. Accounting for adaptation in the macroeconomics of climate change impacts is a relatively new research area (Agrawala and Fankhauser, 2008). Markandya and Watkiss (2010) argued that the number of available studies is small, that estimates can only be treated as indicative, and that studies deal inadequately with uncertainty and equity. The authors also argue that there are major gaps in the discussion of the economic valuation of biodiversity and ecosystem services and that studies omit soft adaptation and adaptive capacity. By considering the sensitivity to extreme events in our approach, we tried to improve on the previous research by accounting for system-wide interdependencies among economic sectors. This approach is important, as extreme and catastrophic climate events disrupt business networks that span all sectors.

Second, the value of the sensitivity index reminds us that although most economic activity in services and industry takes place indoors, and a portion of the economy is dematerialized, a significant fraction $(25 \%)$ of the human activity remains exposed to climate and climate change. Our estimate is larger than that of the World Bank (2006, Annex K) study, which estimated the climate-sensitive portion of gross domestic investment for developing countries to be between 2\% and 10\% (Margulis et al., 2009, Table 1). However Parry et al. (2009) argued that the result from the World Bank (2006) study and the Stern (2006) review (which largely reused the former's results) were underestimated by two to three times.

Third, economic sectors appear unequally exposed to climate change. The EACC synthesis report (Margulis et al., 2010, Table ES-2) concluded that infrastructure, coastal zones, and water capture the bulk of adaptation costs. However, our exhaustive approach weighting economic sectors by their size highlights different sectors. Construction and housing appears to be the most problematic sector followed by utilities and agriculture and recreational services. The last two sectors are notably vulnerable but do not carry much weight overall. The reason for this apparent discrepancy is that the Margulis et al. (2010) study defines sectors in a bottom-up manner; in contrast, we used a top-down approach. The bottom-up method was disaggregated by region, and distinguished the following sectors: infrastructure; coastal zones; water supply and flood protection; agriculture, forestry, fisheries; human health; and extreme weather events. This list is not comparable to the systematic list of macroeconomic sectors used in GTAP. 


\begin{tabular}{|c|c|c|c|c|c|c|c|}
\hline Sector & $\begin{array}{c}\text { specific of a } \\
\text { climate }\end{array}$ & $\begin{array}{l}\text { outdoor } \\
\text { activity }\end{array}$ & $\begin{array}{l}\text { sensitive to } \\
\text { climatic } \\
\text { extreme } \\
\text { events }\end{array}$ & $\begin{array}{c}\text { sensitivity } \\
\text { index } \\
\text { (percent) }\end{array}$ & $\begin{array}{l}\text { defensivity } \\
\text { index } \\
\text { (percent) }\end{array}$ & $\begin{array}{c}\text { share in } \\
\text { capital } \\
\text { (percent) }\end{array}$ & $\begin{array}{c}\text { share in } \\
\text { value added } \\
\text { (percent) }\end{array}$ \\
\hline Agriculture & ++ & ++ & + & $86 \%$ & $12 \%$ & $2.02 \%$ & $3.44 \%$ \\
\hline Wood products & ++ & + & ++ & $86 \%$ & $15 \%$ & $0.97 \%$ & $0.9 \%$ \\
\hline Transport & - & + & ++ & $53 \%$ & $15 \%$ & $2.66 \%$ & $2.84 \%$ \\
\hline Electricity & + & - & ++ & $53 \%$ & $10 \%$ & $1.69 \%$ & $1.04 \%$ \\
\hline Water & ++ & - & + & $53 \%$ & $7 \%$ & $0.24 \%$ & $0.22 \%$ \\
\hline Construction & ++ & ++ & + & $86 \%$ & $12 \%$ & $4 \%$ & $5.32 \%$ \\
\hline Communication & - & - & + & $20 \%$ & $7 \%$ & $0.56 \%$ & $0.43 \%$ \\
\hline Insurance & - & - & ++ & $33 \%$ & $10 \%$ & $0.19 \%$ & $0.41 \%$ \\
\hline Business services & - & - & + & $20 \%$ & $7 \%$ & $3 \%$ & $2.12 \%$ \\
\hline Recreational services & + & + & + & $60 \%$ & $10 \%$ & $2.88 \%$ & $2.56 \%$ \\
\hline Public & - & - & + & $20 \%$ & $7 \%$ & $1.41 \%$ & $3.28 \%$ \\
\hline Dwellings & + & - & + & $40 \%$ & $7 \%$ & $5.23 \%$ & $2.49 \%$ \\
\hline Other $^{\dagger}$ & - & - & - & & & & \\
\hline
\end{tabular}

Table 1: Vulnerability to climate change by economic sector. The first three columns are qualitative assessments by the authors, which are used to derive the columns "sensitivity index" and "defensivity index". The sensitivity index determines the share of the sector that needs climate adaptation, and the defensivity index describes the fraction of protection capital. The column "share in capital" presents sensitive capital in a given sector as a percentage of total capital across all sectors. Similarly, the column "share in value added" presents sensitive value added in a given sector as a percentage of total value added across all sectors. ${ }^{\dagger}$ Other sectors are the following: Textile, Processed food, Minerals, Oil Products, Coal, Gas, Paper, Plastic, Vehicles, Electronic, Machinery, Manufacture, Trade, Financial 


\section{Capital adaptation with a growing temperature}

As a first step, we present a notably simple model of capital adaptation to climate change with an exogenous temperature change. The capital under consideration is exposed to climate and must be adapted to the current climate to be efficient. In this section, only one type of capital is considered; it is considered to be fully vulnerable to climate change.

We assume that there are different categories of this capital. Each category is designed for a specific climate and becomes abruptly inefficient when climate changes too much. This is inspired from the concept of a coping range discussed, for example, by Smit et al. (2000). Climate change is assumed to be linked to the world average temperature change.

A category of protection capital $K_{j}$ is defined by the global average temperature $\theta^{j}$ for which it is best adapted. Denoting the realized temperature in the model at date $t$ to be $\theta_{t}$, we use an efficiency function $g\left(\theta_{t}-\theta^{j}\right)$ such that $g(0)=1$ and $g$ equals zero when the temperature changes more than $w / 2$. The function we use here is as follows:

$$
\begin{aligned}
& g(x)=1,|x| \leq w / 2 \\
& g(x)=0,|x|>w / 2
\end{aligned}
$$

Thus, $g$ is symmetric, with warming and cooling being similarly harmful. Taking the example of sea-level rise, this hypothesis amounts to assigning equivalent costs for sealevel rise and sea-level fall, this condition corresponds to the costs of relocating at an optimal distance from the sea.

We assume that different kinds of capital corresponding to different climates are perfect substitutes, and therefore the total efficient capital $\tilde{K}$ is computed by summing up the different stocks of capital, each with its own efficiency:

$$
\tilde{K}=\sum_{j} g\left(\theta_{t}-\theta^{j}\right) K_{j}
$$

The exposed capital depreciates at the constant rate $\delta$ and enters a production function $F$, which also depends on an exogenous labor input $L_{t}$. Discounted utility $u$ is maximized subject to $\beta$ (the discount factor), $P_{t}$ (the exogenous population), and $C_{t}$ (consumption). Therefore, the program to be solved is the following:

$$
\begin{gathered}
\max _{C_{t}, I_{t}^{j}} \sum_{t} \beta^{t} P_{t} u\left(\frac{C_{t}}{P_{t}}\right) \\
F\left(\sum_{j} g\left(\theta_{t}-\theta^{j}\right) K_{j}, L_{t}\right)=\sum_{j} I_{t}^{j}+C_{t}
\end{gathered}
$$

with $\forall j$

$$
K_{t+1}^{j}=(1-\delta) K_{t}^{j}+I_{t}^{j}
$$

In such a setting, with increasing $\theta_{t}$, it is clear that only one type of capital is invested in during each period: the capital type with the highest associated temperature 
that is also already efficient, $\theta^{j}=\theta_{t}+w / 2$. Any other investment would lead to less aggregate capital, now if $g\left(\theta_{t}-\theta^{j}\right)=0$ or when the temperature has grown to $\theta_{t}+w / 2$. The model is thus equivalent to a model with capital with a finite lifetime:

$$
\tilde{K}_{t+1}=\sum_{\tau=\theta^{-1}\left(\theta_{t}-w\right)}^{t}(1-\delta)^{t-\tau} I_{\tau}
$$

where the $j$ index has been dropped from investment because investment is associated with a unique temperature.

This kind of problem has been solved, for example, in Benhabib and Rustichini (1991). Assuming that temperature increases linearly at the rate $\phi$, the efficient capital dynamics are characterized by

$$
\tilde{K}_{t+1}=(1-\delta) \tilde{K}_{t}+I_{t}-I_{t-\frac{w}{\phi}-1}(1-\delta)^{\frac{w}{\phi}+1}
$$

First order conditions lead to

$$
\begin{array}{r}
-(1-\delta)^{\frac{w}{\phi}+1} \beta^{\frac{w}{\phi}+1} \frac{u^{\prime}\left(\frac{C_{t+\frac{w}{\phi}+1}}{P_{t+\frac{w}{\phi}+1}}\right)}{u^{\prime}\left(\frac{C_{t}}{P_{t}}\right)} F_{1}\left(\tilde{K}_{t+\frac{w}{\phi}+1}, L_{t+\frac{w}{\phi}+1}\right)+F_{1}\left(\tilde{K}_{t}, L_{t}\right) \\
=\frac{u^{\prime}\left(\frac{C_{t-1}}{P_{t-1}}\right)}{\beta u^{\prime}\left(\frac{C_{t}}{P_{t}}\right)}-(1-\delta)
\end{array}
$$

In the following analysis, labor is set equal to the population $P_{t}$ multiplied by a geometrically increasing technical progress factor $\frac{L_{0}}{P_{0}}(1+\kappa)^{t}$. Population also increases geometrically at a rate of $\mu$, such that $P_{t}=P_{0}(1+\mu)^{t}$. Function $F$ is a standard neoclassical production function, where $f$ the per unit of labor production function. We use a constant intertemporal elasticity of substitution utility function: $u^{\prime}(C)=C^{-\tau}$. Defining $c_{t}$ and $\tilde{k}_{t}$ the per-unit-of-labor variables corresponding to $C_{t}$ and $\tilde{K}_{t}$ and $c$ and $\tilde{k}$ the corresponding stationary state variables, one obtains:

$$
f^{\prime}(\tilde{k})=\frac{\frac{(1+\kappa)^{\tau}}{\beta}-(1-\delta)}{1-\left((1-\delta) \beta(1+\kappa)^{-\tau}\right)^{\frac{w}{\phi}+1}}
$$

The social discount rate is therefore higher than in the case of depreciation in infinite time: there is less efficient capital than in the standard Ramsey model.

However, investment as a function of efficient capital is higher because there is some capital that becomes inefficient sooner:

$$
i=\frac{(1+\kappa)(1+\mu)-(1-\delta)}{1-\left(\frac{1-\delta}{(1+\kappa)(1+\mu)}\right)^{\frac{w}{\phi}+1}} \tilde{k}
$$

The total amount of capital $K=\sum_{j} K_{j}$ follows classical capital dynamics; therefore, the stationary level of per-unit of labor capital $k$ is given by the following:

$$
k=\frac{1}{1-\left(\frac{1-\delta}{(1+\kappa)(1+\mu)}\right)^{\frac{w}{\phi}+1}} \tilde{k}
$$


Using a Cobb-Douglas function with capital share $\alpha$, the saving rate $s$ is

$$
s=\frac{i}{y}=\alpha \frac{1-\left((1-\delta) \beta(1+\kappa)^{-\tau}\right)^{\frac{w}{\phi}+1}}{\frac{(1+\kappa)^{\tau}}{\beta}-(1-\delta)} \frac{(1+\kappa)(1+\mu)-(1-\delta)}{1-\left(\frac{1-\delta}{(1+\kappa)(1+\mu)}\right)^{\frac{w}{\phi}+1}}
$$

The comparison to the corresponding saving rate with infinitely lived capital, $s^{\infty}$ gives us

$$
\frac{s}{s^{\infty}}=\frac{1-\left((1-\delta) \beta(1+\kappa)^{-\tau}\right)^{\frac{w}{\phi}+1}}{1-\left(\frac{1-\delta}{(1+\kappa)(1+\mu)}\right)^{\frac{w}{\phi}+1}} \approx \frac{1-(1-\delta-\zeta-\kappa \tau)^{\frac{w}{\phi}+1}}{1-(1-\delta-\mu-\kappa)^{\frac{w}{\phi}+1}}
$$

with $\zeta$ the pure time preference rate. Therefore $s>s^{\infty}$ if $\zeta+\kappa(\tau-1)>\mu$, which is the general case.

In summary, the optimal strategy minimizes accelerated obsolescence by installing the type of protection capital that is just efficient today but is adapted to future climate conditions. Premature retirement of capital due to climate change has a similar effect as would an increase in the social discount rate: along the optimal path, the marginal productivity of the remaining capital should be higher. The optimal saving rate is increased when the condition in the previous paragraph holds: in that case, investment increases, even though the remaining capital stock has decreased.

\section{An optimal growth model with adaptation}

We now turn to a case that is more complicated, but also more relevant. Indeed, temperature change is now endogenously determined, being linked to the economic production through emissions, a carbon cycle and temperature increase. Additionally, population does not increase geometrically but follows a SRES scenario (Intergovernmental Panel on Climate Change, 2000). This model cannot be solved analytically. The optimal growth model with climate change adaptation and no uncertainty resulting is still inspired by the classical Ramsey/Cass/Koopmans model, as well as from the DICE (Nordhaus, 1994) and RESPONSE (Ambrosi et al., 2003) integrated assessment models. The innovation is that we introduce protection capital in addition to the productive capital as outlined in section 2. Protection capital efficiency and the link with the temperature are similar, as in the approach presented in the previous section, although the efficiency function is slightly more complex.

The objective is to maximize the intertemporal sum of the discounted utility of consumption. Economic output is a function of labor, which is still exogenous, and capital. Economic production leads to $\mathrm{CO}_{2}$ emissions; these emission determine climate change via a simple carbon cycle and global warming submodel. Climate change reduces the productivity of the aggregate economy.

Adaptation is introduced as follows (see figure 1 again). As in section 3, we assume that there are different categories of protection capital. Each is designed for a specific climate, and becomes abruptly inefficient when climate changes too much, as already 


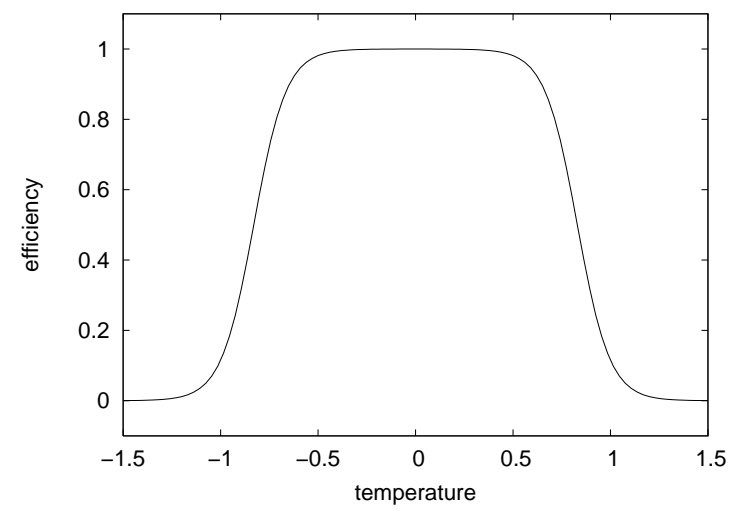

Figure 2: Efficiency of the protection capital as a function of the difference between the actual temperature and the temperature associated with the protection capital.

described in the previous section. Climate change is still represented by the amount of global warming.

In this section, we use a different function for the efficiency of the protection capital, $g\left(\theta_{t}-\theta^{j}\right)$. The function is still symmetric and such that $g(0)=1$ and $g$ becomes small when the temperature difference becomes large. However, now the transition is smoother, see figure 2.

The function is specified with two parameters, parameter $w$ controls the width $g(w / 2)=g(-w / 2)=1 / 2$, while parameter $z$ controls the abruptness of the efficiency change. More precisely:

$$
g(x)=\frac{1+e^{-z w}}{\left(1+e^{-z(x+w / 2)}\right)\left(1+e^{-z(-x+w / 2)}\right)}
$$

We assume that different kinds of adaptation measures can be superimposed to protect the exposed productive capital; that is, protection capital stocks are perfect substitutes. Improved adaptation could also be achieved by augmenting the range of temperatures that a given type of capital can handle (increasing $w$ ), or by the use of capital that becomes obsolete faster (Fankhauser et al., 1999). In this equation, we consider neither those opportunities nor their cost.

The total efficient protection capital is computed by summing up the different stocks of protection capital, each with its own efficiency, as in the previous section (1):

$$
\text { Efficient protection capital stock }=\sum_{j} g\left(\theta_{t}-\theta^{j}\right) K_{j}
$$

Even in the absence of climate change, protection capital is needed to adapt to the current climate. In the no-climate change scenario (BAU), there is only one type of protection capital, $K^{B A U}$ which is characterized by an efficiency of 1 . 
A fraction $v K$ of productive capital is exposed to climate and must be combined with the protection capital to enter the production function. It is assumed that the exposed capital and the protection capital have a constant elasticity of substitution and are complements: they are not useful taken separately.

The capital available for production is the sum of the non-vulnerable capital (1 $v) K$ and the aforementioned combination of exposed and protection capital. Capital and labor are combined using a Cobb-Douglas function. The production $Y$ may be used for investment in productive capital $I$, investment in protection capital $I^{j}$ and consumption $C$. Labor is equal to the population $P$ multiplied by a geometrically increasing technical progress factor $\mu(1+\kappa)^{t}$.

Denoting the per-labor-unit variables with lower case letters, for example $c=$ $\frac{C}{P \mu(1+\kappa)^{t}}$, the production function is:

$$
y_{t}=\left[(1-v) k_{t}+\left(\eta\left(v k_{t}\right)^{\rho}+\gamma\left(\sum_{j} g\left(\theta_{t}-\theta^{j}\right) k_{t}^{j}\right)^{\rho}\right)^{\frac{1}{\rho}}\right]^{\alpha}
$$

The remainder of the model is classical. Let $u$ be a utility function with constant intertemporal elasticity of substitution: $u^{\prime}(C)=C^{-\tau}$. The objective is as follows:

$$
\max _{\substack{j \\ i_{t}, i_{t}, c_{t}}} \sum_{t=0}^{140} \beta^{t} P_{t} u\left(c_{t} \mu(1+\kappa)^{t}\right)
$$

Such that

$$
\begin{aligned}
y_{t} & =c_{t}+i_{t}+\sum_{j} i_{t}^{j} \\
k_{t+1} & =\frac{P_{t}}{P_{t+1}(1+\kappa)}\left((1-\delta) k_{t}+i_{t}\right) \\
k_{t+1}^{j} & =\frac{P_{t}}{P_{t+1}(1+\kappa)}\left((1-\delta) k_{t}^{j}+i_{t}^{j}\right) \quad \forall j \\
\frac{E_{t}}{E_{0}} & =\xi_{t} e^{\psi t} \frac{y_{t} P_{t}(1+\kappa)^{t}}{y_{0} P_{0}}
\end{aligned}
$$

In the emission dynamics, the factor $\xi_{t}$ corresponds to the transition from the current trend to the projected trend. The other factor is an exogenous energy efficiency improvement; this setup is used in Nordhaus (1994), for example. The carbon cycle and temperature equations are the same as in Nordhaus and Boyer (2000), with the calibration of the temperature cycle following Ambrosi et al. (2003) (not shown here).

\section{Results and sensitivity analysis}

The model was implemented in GAMS. We used section 2 estimates and a SRES A1 scenario trajectory to calibrate the parameters (see appendix A). 


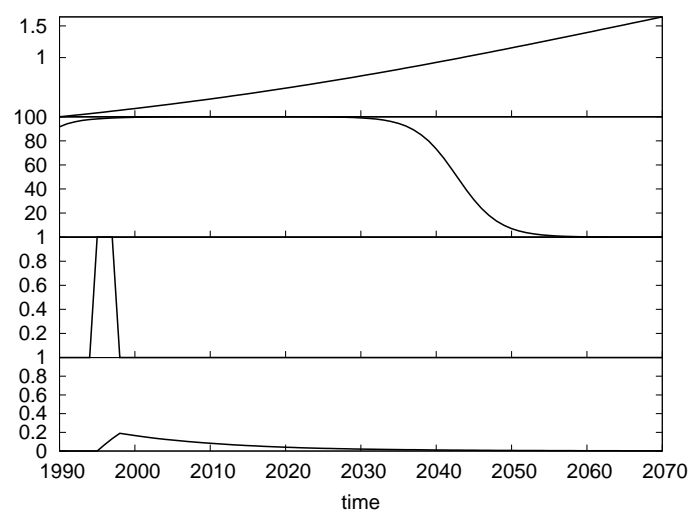

Figure 3: Evolution of the type 10 protection capital, associated with a temperature increase of $1.26^{\circ} \mathrm{C}$. From top to bottom: global temperature increase $\theta_{t}$, efficiency of the capital $g\left(\theta_{t}-\theta^{10}\right)$, investment in that type of capital scaled by the total amount of investment in protection capital $\frac{i_{t}^{10}}{\sum_{j} i_{t}^{j}}$ and capital 10 stock scaled by the total amount of protection capital.

The model results are best explained by looking first at a specific type of protection capital. Consider, for example, the capital associated with $j=10$. This capital corresponds to adaptation measures designed to work optimally for a temperature increase of $\theta^{10}=1.26^{\circ} \mathrm{C}$ above the pre-industrial era. This capital becomes inefficient only when global average temperature increases by over $\theta^{10}+w=2.9^{\circ} \mathrm{C}$.

Figure 3 shows how the global temperature, this capital efficiency $g\left(\theta_{t}-\theta^{10}\right)$, the optimal investment in this capital $i_{t}^{10}$ and the capital stock $K_{t}^{10}$ evolve over time. The investment $I_{t}^{10}$ is scaled by the total amount of protection investment, and the capital $K_{t}^{10}$ is scaled with the total protection capital.

The third panel in figure 3 shows a pulse of investment in type-10 protection capital, as in the analytic exercise in section 3. This class of protection investment is used only in the years 1995, 1996, and 1997 (optimization begins in 1990); however, during these three years, type-10 protection capital is used exclusively.

Moving now to the second and fourth panels in the figure, we see that investment occurs at a time when efficiency is already high but not yet $100 \%$. Investment in capital occurs as soon as it is productive; this is consistent with the result from section 3 . Full capital efficiency is reached only about ten years after the investment and lasts approximately two decades. At the tail end of the capital efficiency, when the efficiency begins to decrease due to excessive global warming, most of the protection capital stock has decayed.

Thus, along the optimal trajectories, sunk costs are incurred at the beginning and at the end of the capital's lifetime when capital is not fully efficient. The climate change is too rapid to allow for the use of capital that is as efficient as in the baseline. Replacement must occur before new capital is fully efficient and inefficient capital still 


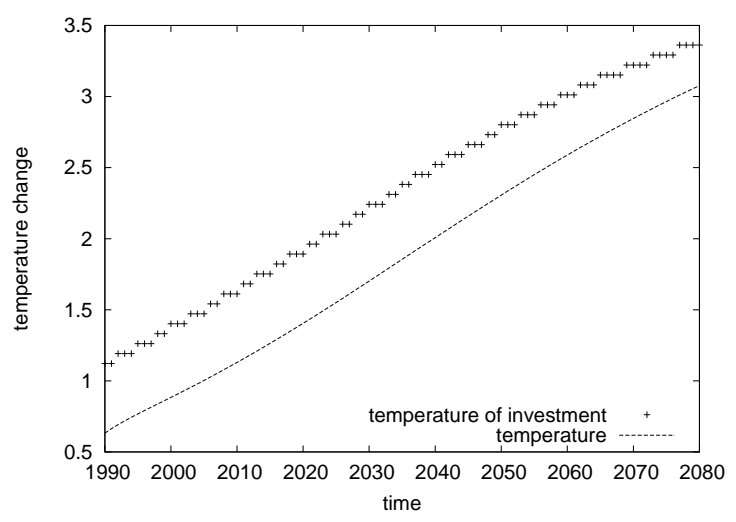

Figure 4: Optimal investment in protection capital (++ line) anticipates the atmospheric temperature (dashed line) by about two decades, or one half of a degree.

remains; this second fact is also consistent with the results of the analytic model.

At its peak, type-10 capital represents only $20 \%$ of the total protection capital. Along the optimum trajectory, the model representative investor adapts every 2 to 3 years to global warming by calling in a different kind of protection capital. Consequently, the total protection capital stock is made from a variety of different kind of capital.

This can also be seen in figure 4. The figure shows the realized temperature $\theta_{t}$ and the temperature $\theta^{j}$ associated with the kind of investment $I_{t}^{j}$ (in proportion to the different kinds of investment made in the given period). The figure shows that investment leads the temperature increase by about two decades. Put differently, at any time protection investment is designed for a temperature about one-half of a degree above the current temperature.

Examining now the results from the costs perspective, the model balances two costs:

- The economic inefficiencies caused by climate change. In our setting this damage is associated with using a protection capital efficiency that is lower than in the baseline (BAU) without climate change. Denoting the BAU protective capital quantity as $K^{B A U}$, this damage is therefore present when

$$
\sum_{j} g\left(\theta_{t}-\theta^{j}\right) K_{t}^{j}<K^{B A U}
$$

- Over-investment in protection capital relative to the baseline. This happens if

$$
\sum_{j} K_{t}^{j}>K^{B A U}
$$




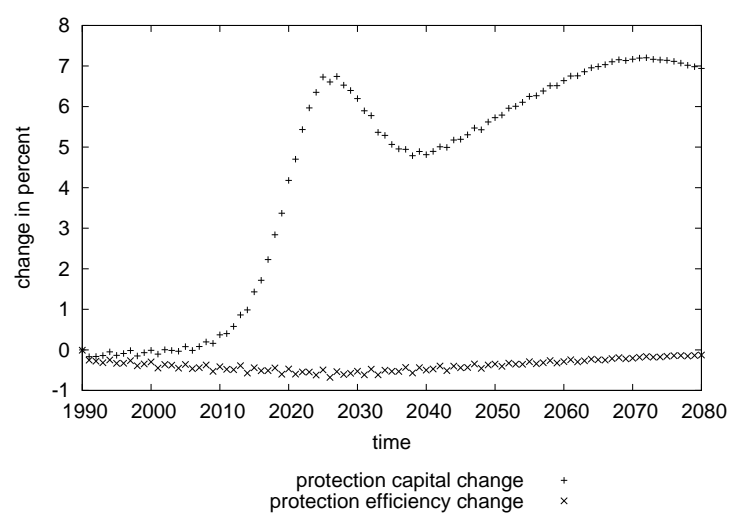

Figure 5: The balance of costs. Compared to the BAU scenario, the optimal trajectory invests more in protection capital, but the efficiency losses remain small.

Figure 5 shows how the protection capital efficiency and the protection capital amount change relative to the BAU protection capital (without climate change). This figure demonstrates that most of the cost corresponds with an additional investment peaking at approximately 7\%. It seems to be preferable to bear sunk costs than to suffer from maladaptation. This is consistent with the analytic model, which exhibits an increase in the saving rate. This change is also in line with the analytic model, as this is approximately the difference in capital stock with respect with to a simple Ramsey model when capital is efficient for 40 years.

Turning to the net costs of climate change, figure 6 shows the consumption losses over time. An interesting result is that in the earliest periods, the consumption is higher in the case of climate change. Investment is directed to a type of capital associated with a higher temperature from the very beginning, but the amount of investment is lower than in the baseline. This effect is not observed in the analytic model in the steady state and is caused by the interaction between the discount rate and the imbalance between productive and protection capital in the first years. Indeed, although protection investments increase, investment in productive capital can decrease to maintain the optimal ratio between the two types of capital; total investment decreases.

In figure 5 and 6 a bulge can be seen near the year 2025. Most of this bulge is caused by the suboptimality of the preexisting protection capital stock available in the first period. The initial protection capital is composed of only a single type; there is no anticipation of future climate change. If the initial protection capital is instead a mix of capital types with a structure similar with the structure resulting from the optimization, the bulge almost disappears. A small increase remains approximately 2025, however, because the rate of climate change is the highest around this year.

Three sensitivity analyses were performed. First, table 2 shows the utility loss for different values of $\pi_{s}, \pi_{p}$ and $w$, which are notably uncertain parameters. Second, bestand worst-case scenarios are compared to the central case, as seen in table 3. The 


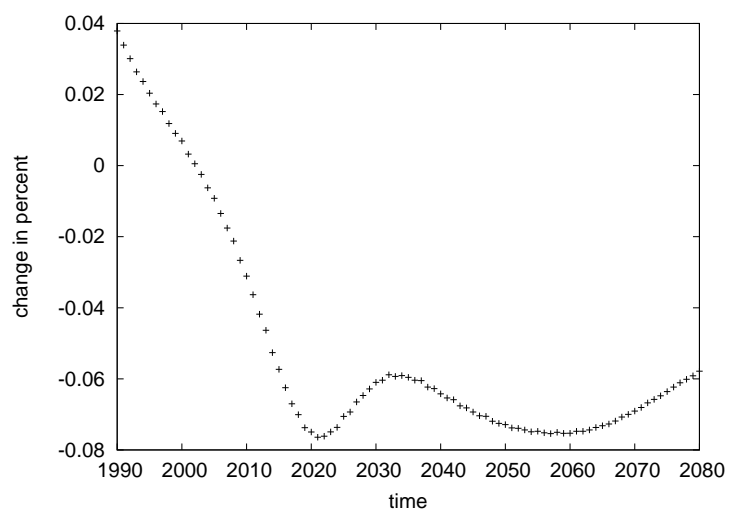

Figure 6: Consumption change over time in percent.

\begin{tabular}{|c|c|c|c|c|c|c|c|c|c|c|}
\hline \multirow{3}{*}{\multicolumn{2}{|c|}{$\pi_{s}$}} & \multicolumn{9}{|c|}{$\pi_{p}$} \\
\hline & & \multicolumn{3}{|c|}{0.05} & \multicolumn{3}{|c|}{0.1} & \multicolumn{3}{|c|}{0.2} \\
\hline & & 0.12 & 0.24 & 0.29 & 0.12 & 0.24 & 0.29 & 0.12 & 0.24 & 0.29 \\
\hline \multirow{4}{*}{$w$} & 1.46 & 0.002 & 0.004 & 0.005 & 0.004 & 0.009 & 0.010 & 0.009 & 0.017 & 0.021 \\
\hline & 1.66 & 0.001 & 0.003 & 0.003 & 0.003 & 0.006 & 0.007 & 0.006 & 0.011 & 0.013 \\
\hline & 2.26 & 0.000 & 0.001 & 0.001 & 0.001 & 0.002 & 0.002 & 0.002 & 0.003 & 0.004 \\
\hline & 2.66 & 0.000 & 0.000 & 0.000 & 0.000 & 0.001 & 0.001 & 0.001 & 0.002 & 0.002 \\
\hline
\end{tabular}

Table 2: Sensitivity analysis on $\pi_{s}, \pi_{p}$ and $w$. Result is the total intertemporal utility loss, compared with the no-climate-change baseline, in percent. The other parameters assume their default values.

third analysis considers the consequences of a delay in implementation of adaptation measures, which could be explained if adaptation was not carried out with perfect foresight. The result is shown in the bottom row of table 3 .

The total intertemporal utility increases when $w$ increases: having protection capital that remains efficient longer is better. In the simulated efficiency range of $1.5-2.7^{\circ} \mathrm{C}$, the utility loss remains modest in all cases. It is approximately zero when $w$ is more than $2.5^{\circ} \mathrm{C}$.

To analyze the results further, two extreme cases are examined: a worst-case scenario and a best-case scenario. These are defined by changing the climate sensitivity $T_{2 \times}$, the protection efficiency range $w$, the fraction of vulnerable capital $\pi_{s}$ and the fraction of protection capital $\pi_{p}$, as table 3 shows. In the best-case scenario, protection capital has a wide efficiency range, climate sensitivity is low, the fraction of capital exposed climate is low and not much protection capital is needed. The order of magnitude of the utility loss changes but remains relatively modest, even in the worst-case scenario. The optimal investment strategy remains qualitatively the same: a sequence of pulses in protection capital, anticipating changes to remain adapted. 


\begin{tabular}{lccccc}
\hline scenario & $w$ & $\pi_{p}$ & $\pi_{s}$ & $T_{2 \times}$ & result \\
\hline worst case & 1.44 & 0.15 & 0.5 & 4.5 & 0.044 \\
central case & 1.66 & 0.1 & 0.24 & 3.5 & 0.005 \\
best case & 2.66 & 0.05 & 0.12 & 2.5 & 0.00005 \\
\hline delayed & \multicolumn{5}{c}{ same as central case } \\
\hline
\end{tabular}

Table 3: Sensitivity analysis parameter values and results. Result is the total intertemporal utility loss, compared with the no-climate-change baseline, in percent. The key parameters in the columns are the efficiency range of protection capital $w$, the fraction of protection capital $\pi_{p}$, the fraction of exposed capital $\pi_{s}$ and the climate sensitivity $T_{2 \times}$. The delayed scenario only allows adaptation to start when efficiency loss in vulnerable sectors has reached $2 \%$.

The importance of the initial situation highlights the possible costs arising from delays in implementing adaptation methods to keep up with the rate of climate change. This issue is important because, as reported in Schneider et al. (2000) or Tol et al. (1998) adaptation to climate change is often reactive.

To examine the costs of late adaptation, we constrained the model such that adaptation is only allowed when the vulnerable sectors production has been reduced by $2 \%$. Therefore, before 2019 in the central case, protection capital is constrained to correspond to the initial temperature. The costs significantly change in that simulation: production is reduced in the years preceding 2019, and additional investment becomes substantial. Overall, as seen in the bottom row of table 3 , the utility loss is an order of magnitude larger than in the central case: delayed adaptation would be costly.

\section{Discussion and concluding remarks}

Many assumptions were made in the macroeconomic model of adaptation used above. For instance, emission reductions are not considered, and there is no direct climate damage function. In our view, the most limiting assumptions are that the production function has a single factor, and anticipation is perfect without uncertainty. In certain sectors of the economy, protection capital will not be available as easily as represented in the model, especially for larger changes in climate. The depreciation rate of physical capital also differs across sectors. Real economies could adapt structurally by moving towards less sensitive sectors or those which are perceived to be easily protected. Development may lead to inefficient behaviors, such as settling in flood-prone areas. Mistakes may be made when implementing adaptation measures because of the practical issues associated with risk perception, irrational behavior and policy.

To sum up the results, we assessed that about a quarter of the world's productive capital is sensitive to climate. While currently the majority of economic activity occurs sheltered indoors, a large number of economic sectors, such as housing and infrastructure, are directly exposed to extreme weather events or must still adapt to local climatic conditions.

There is a dynamic tradeoff to be made between the costs of adaptation and the 
economic productivity losses due to climate change. We presented a simple analytical model and a stylized macroeconomic growth model to examine this tradeoff. The results show that along an optimal investment path, the protection capital installed is not designed for the current climate but anticipates future warmer conditions. Additionally, while there is additional investment compared to a no-climate-change baseline, the overall cost to adapt is relatively low compared with the potential losses from maladaptation. Overinvestment in protection capital allows the economy to stay consistently well-adapted to climate and avoid transient maladaptation costs.

Adaptation measures are sunk costs and may become inefficient when climate changes more in the long run. Thus, there is interplay between the speed of climate change and the natural replacement cycle of protection capital. Our results lead us to stress that in case of imperfect foresight, letting climate change accelerate may lead to situations where many adaptation measures become obsolete and need to be replaced before they reach their expected lifetime.

The numeric integrated assessment analysis suggests that although there is additional investment in protection capital by several percentage points, the consumption losses are less than one-tenth of one percent annually. This finding is observed mainly because the share of protection investment in total investment is small: we estimated that a small amount of protection capital, less than ten percent of the sensitive capital, was needed to be adapted to a changed climate. Another driver of this result is the assumption of separability between protection and exposed capital. This hypothesis could be challenged in the case of infrastructure and housing: when the protection capital is embedded within infrastructure, changing the climate specificity may be sufficiently costly that rebuilding the whole infrastructure may prove to be cheaper.

Along the optimal pathway, adaptation is proactive and anticipates warming approximately twenty years ahead; our results suggest that in a "perfect" world aggregate adaptation costs could be low. A sensitivity analysis where adaptation only starts after vulnerable sectors are impacted increases costs by a factor of ten, stressing the potential damage of delaying adaptation.

\section{References}

Shardul Agrawala and Samuel Fankhauser, editors. Empirical Estimates of Adaptation Costs and Benefits: A Critical Assessment, chapter 2. OECD, 2008. ISBN 9789264046030. URL http://www.oecd.org/env/cc/ecoadaptation.

Philippe Ambrosi, Jean-Charles Hourcade, Stéphane Hallegatte, Franck Lecocq, Patrice Dumas, and Minh Ha-Duong. Optimal control models and elicitation of attitudes towards climate change. Environmental Modeling and Assessment, 8(3):135147, 2003. doi: 10.1023/A:1025586922143. Reprinted in J. A. Filar and A. Haurie (eds) "Uncertainty and environmental decision making. Handbooks on OR/MS".

Jess Benhabib and Aldo Rustichini. Vintage capital, investment, and growth. Journal of Economic Theory, 55(2):323-339, 1991.

Kelly de Bruin, Rob Dellink, and Richard Tol. AD-DICE: an implementation of 
adaptation in the DICE model. Climatic Change, 95:63-81, 2009. ISSN 01650009. doi: 10.1007/s10584-008-9535-5. URL http://dx.doi.org/10.1007/ s10584-008-9535-5.

Samuel Fankhauser, Joel B. Smith, and Richard S.J. Tol. Weathering climate change: some simple rules to guide adaptation decisions. Ecological Economics, 30:67-78, 1999.

GTAP. Global Trade Analysis Project, 1997. URL https://www.gtap.agecon . purdue.edu/default.asp.

Stéphane Hallegatte. The long time scales of the climate-economy feedback and the climatic cost of growth. Environmental Modeling and Assessment, 10(4):277-289, October 2005.

Stéphane Hallegatte. Strategies to adapt to an uncertain climate change. Global Environmental Change, 19:240-247, 2009. doi: 10.1016/j.gloenvcha.2008.12.003.

Intergovernmental Panel on Climate Change. Special Report on Emissions Scenarios. Cambridge University Press, 2000. ISBN 978-0521804936. URL http://www . ipcc.ch/ipccreports/sres/emission/index.htm.

IPCC. Climate Change 2007: Synthesis Report. Contribution of Working Groups I, II and III to the Fourth Assessment Report of the Intergovernmental Panel on Climate Change. Intergovernmental Panel on Climate Change, 2007. URL http://www.ipcc.ch/publications_and_data/publications_ipcc_ fourth_assessment_report_synthesis_report.htm.

David L. Kelly, Charles D. Kolstad, and Glenn T. Mitchell. Adjustment costs from environmental change. Journal of Environmental Economics and Management, 50: 468-495, 2005. doi: 10.1016/j.jeem.2005.02.003.

Sebastian Kopf, Minh Ha-Duong, and Stéphane Hallegatte. Using maps of city analogues to display and interpret climate change scenarios and their uncertainty. Natural Hazards and Earth System Sciences, 8(4):905-918, August 2008. URL http://www . nat-hazards-earth-syst-sci.net/8/905/2008/ nhess-8-905-2008.html. NHESS is an open access journal of the European Geosciences Union.

Sergio Margulis, Ana Bucher, David Corderi, Urvashi Narain, Hawanty Page, Kiran Pandey, Thi Trang Linh Phu, Nivular Ahmed, Carina Bachofen, Anne Kuriakose, Robin Mearns, Nicolas Perrin, Brian Blankespoor, Susmita Dasgupta, Siobhan Murray, Elizabeth Cushion, Lidvard Gronnevet, Laurent Cretegny, Prodipto Ghosh, Gordon Hughes, Benoit Laplante, Larissa Leony, Gerald Nelson, Robert Nicholls, Robert Schneider, Ken Strzepek, and David Wheeler. The economics of adaptation to climate change. final methology report. Technical report, The World Bank, February 2009. URL http://climatechange.worldbank.org/climatechange/ content/economics-adaptation-climate-change-study-homepage. 
Sergio Margulis, Gordon Hughes, Robert Schneider, Kiran Pandey, and Urvashi Narain and. The economics of adaptation to climate change. synthesis report. Technical report, The World Bank, February 2010. URL http://climatechange.worldbank.org/climatechange/content/ economics-adaptation-climate-change-study-homepage.

Anil Markandya and Paul Watkiss. Potential costs and benefits of adaptation options: A review of existing literature. Technical Report FCCC/TP/2009/2/Rev.1, UNFCCC, May 11 2010. URL http://adaptationonline.blogspot.com/2010/ 01/unf ccc-review-of-adaptation-costs-and.html.

William D. Nordhaus. Managing the Global Commons: The Economics of Climate Change. MIT Press, 1994. ISBN 978-0262-14055-3.

William D. Nordhaus and Joseph Boyer. Warming the World: Economics Models of Global Warming. MIT press, 2000. ISBN 978-0262640541. URL http://www. econ. yale.edu/ nordhaus/homepage/dice_section_I.html.

Brian C. O’Neill, Paul Crutzen, Arnulf Grübler, Minh Ha-Duong, Klaus Keller, Charles Kolstad, Jonathan Koomey, Andreas Lange, Michael Obersteiner, Michael Oppenheimer, William Pepper, Warren Sanderson, Michael Schlesinger, Nicolas Treich, Alistair Ulph, Mort D. Webster, and Chris Wilson. Learning and climate change. Climatic Change, 6(5):585-589, 2006.

Martin Parry, Nigel Arnell, Pam Berry, David Dodman, Samuel Fankhauser, Chris Hope, Sari Kovats, Robert Nicholls, David Satterthwaite, Richard Tiffin, and Tim Wheeler. Assessing the Costs of Adaptation to Climate Change: A Review of the UNFCCC and Other Recent Estimates. International Institute for Environment and Development and Grantham Institute for Climate Change, London, 2009. ISBN 978-1-84369-745-9. URL http://www . iied.org/pubs/pdfs/11501IIED.pdf.

John Reilly and David Schimmelpfennig. Irreversibility, uncertainty and learning: Portraits of adaptation to long-term climate change. Climatic Change, 45:253-278, 2000. doi: 10.1023/A:1005669807945.

Jean-Luc Salagnac. Lessons from the 2003 heat wave: a French perspective. Building Research and Information, 35(4):450-457, 2007.

Stephen H. Schneider, William E. Easterling, and Linda O. Mearns. Adaptation: Sensitivity to natural variability, agent assumptions and dynamic climate changes. $\mathrm{Cli}$ matic Change, 45:203-221, 2000. doi: 10.1023/A:1005657421149.

Barry Smit, Ian Burton, Richard J.T. Klein, and J. Wandel. An anatomy of adaptation to climate change and variability. Climatic Change, 45:223-251, 2000. doi: 10. 1023/A:1005661622966.

Nicholas Stern. The Economics of Climate Change. The Stern Review. Cambridge University Press, 2006. ISBN 9780521700801. 
Richard S. J. Tol, Samuel Fankhauser, and Joel B. Smith. The scope for adaptation to climate change: what can we learn from the impact literature? Global Environmental Change, 8(2):109-123, 1998. doi: 10.1016/S0959-3780(98)00004-1.

J. Jason West, Mitchell J. Small, and Hadi Dowlatabadi. Storms, investor decisions, and the economic impacts of sea level rise. Climatic Change, 48:317-342, 2001. doi: 10.1023/A:1010772132755.

World Bank. Clean energy and development: Towards an investment framework. Technical report, The World Bank, Environmentally and Socially Sustainable Development Vice Presidency, Infrastructure Vice Presidency, April 5 2006. URL http://go. worldbank.org/BEUCQN31A0.

\section{A Calibration}

The emission function parameters and the technical change rate are fitted using the SRES A1 scenario trajectory from the AIM model (Intergovernmental Panel on Climate Change, 2000). The initial protection capital is only composed of one type of capital, which is the capital associated with the initial temperature. It is assumed that at the starting point the economy is on the balanced growth path. To scale the production function, it is assumed that

$$
K_{0}^{T}=(1-v) K_{0}+\left(\eta\left(v K_{0}\right)^{\rho}+\gamma\left(K_{0}^{1}\right)^{\rho}\right)^{\frac{1}{\rho}}
$$

The number of different protection capital types is chosen sufficiently high such that it does not influence the result. In the central case, model parameters are defined as in table 4 below: 


\begin{tabular}{ccc}
\hline$\tau$ & intertemporal elasticity of substitution & 1 \\
$\delta$ & capital depreciation rate & 0.03 \\
$P_{t}$ & population & follows SRES A1 \\
$\kappa$ & technical progress growth rate & calibrated on SRES A1 \\
$\beta$ & discount factor & 0.96 \\
$C_{0}$ & initial consumption ratio & $75 \%$ \\
$Y_{0}$ & total initial capital & $1-C_{0}$ \\
$K_{0}^{T}$ & 作 & $Y_{0} \frac{1-\delta-y_{1} / y_{0}}{K_{0}}$ \\
$\pi_{s}$ & sensitive capital share in capital & $\frac{K_{0}^{1}+v K_{0}}{K_{0}^{T}}=0.24$ \\
$\pi_{p}$ & protection capital share in sensitive capital & $\frac{K_{0}^{1}}{K_{0}^{1}+v K_{0}}=0.1$ \\
$K_{0}^{1}$ & initial protection capital & $\pi_{s} \pi_{p} K_{0}^{T}$ \\
$K_{0}$ & initial productive capital & $K_{0}^{T}-K_{0}^{1}$ \\
$\nu K_{0}$ & sensitive productive capital & $\pi_{s} K_{0}^{T}-K_{0}^{1}$ \\
$\alpha$ & share of capital & initial value \\
$\mu$ & labor parameter & initial value \\
$\psi$ & energy efficiency improvement & calibrated on SRES A1 \\
$\xi_{t}$ & production emission intensity & calibrated on SRES A1 \\
$\rho$ & protection CES parameter & -4 \\
$\eta$ & protection CES parameter & $\left(1-\pi_{p}\right)^{1-\rho}$ \\
$\gamma$ & protection CES parameter & $\pi_{p}^{1-\rho}$ \\
$w$ & width of protection $\left({ }^{\circ} \mathrm{C}\right)$ & 1.66 \\
$z$ & protection efficiency slope & 12 \\
$T_{2 \times}$ & climate sensitivity & 3.5 \\
\hline
\end{tabular}

Table 4: Model parameters, central case. 